\title{
Comparing Signage in Geographic Space: Raising Students Readiness for the Disruptive Age
}

\author{
Siusana Kweldju \\ State University of Malang \\ Malang, Indonesia \\ siusana.kweldju.fs@um.ac.id
}

\begin{abstract}
Do our high school and university graduates have sufficient awareness and aspiration of how to stand out in the global map of competitive job market, for promoting economic growth and social justice in the age of disruptive innovation? This paper proposes a comparative signage task to raise students' awareness to the rapidly evolving world, especially to motivate students' aspiration in the digitaltechnology-driven world. In the task Google Maps can be used to explore the highways of Silicon Valley, and the highways which connect two major cities in Indonesia. The task provides students with a wider life context by connecting classroom learning to real world experiences, and develops their global perspective. Through the comparison students analyse and interpret how different or similar the business activities in an Indonesian region with Silicon Valley. Silicon Valley is used as a benchmark, as it represents a region where the general workforce has mastered the five technologies that play a critical role in disruptive-age innovation: artificial intelligence, advanced robotics, networks, advanced manufacturing and collaborative connected platforms. An example of how to use the strategy is provided.
\end{abstract}

Keywords: instructional strategy, digital disruption, signage, Silicon Valley, awareness raising

\section{INTRODUCTION}

The site of our education has been mostly associated to classrooms and schools. We have overlooked the potential of the streets for our education. Public spaces and road sites are more interesting for those who want to utilize them for a marketplace, sightseeing, wandering and entertainment, rituals and ceremonies. In general, streets are not for education; only street children roam, work, sleep and survive on streets, while taking the risk of being swept away from them. When urban youth are linked to streets, they are associated to delinquancy and a waste of time. In contrast, this paper innovatively adopts the street or the scene of public spaces for educational purposes.

The present paper proposes an innovative instructional strategy called "A Comparative Signage Task in Geographic
Space" (CST) for enriching students' learning experience. The comparative aspect of the strategy is to promote the students' higher order thinking skills and to raise their awareness and readiness to face the age of disruption, through answering the question: "How do students critically evaluate the differences between the signage found on the highway between two major cities in Indonesia (e.g. Malang-Surabaya Highway) and the signage between San Fransisco and San Jose (i.e. Silicon Valley, Ca.)?" Comparing the commercial signs found on the highways students can find a stark contrast of economic activities-production and consumption-in the two populations. Usually linguistic landscapes or signage studies are studied in urban cores, but in the present task it is done on the signage of highways.

\section{INNOVATIVE INSTRUCTIONAL STRATEGIES}

Innovative instructional strategies are important, because it is unlikely for students to innovatively function in the age of disruption, when the school does not innovatively nurture and prepare them. Even Christenson et al. posit that the core of innovation is to be radical and to utilize distinctly different trajectory [1], in order to disrupt the steady and incremental movement of change. In fact, learning will be more successful when it takes place in diverse situations.

With the mounting pressure to prepare students to be lifelong learners in the age of disruption, social studies instruction should not only bring the knowledge from the streets and the real world around them into the students' coursebooks in the classroom, but students should also be brought to the street; they were guided and motivated to make themselves the critical and creative observers of the real streets and the world around them. As a way of social studies instruction, the strategy contributes to the effort of providing students with as various ways of instructions as possible. Having and being skillful in various strategies of learning, students will become more independent [2]. Accordingly, they will better understand their learning and themselves, and optimize their roles in the society; they can also better understand and respect other people, and learn from them, and be more prepared to be 
successful in their future. In this age of disruption, nobody can rely on one strategy, although it may previously be successful.

\section{A. Silicon Valley: The Benchmark}

There are a lot of countries with their respective high tech innovators and corporations that students can learn as a benchmark. However, in this task the benchmark to use is the street environment in Silicon Valley for its leadership in high technology and for its leading potential to survive in the digital age. The signs found along the freeway of Silicon Valley is a good regional indicator for: its tech startups and entrepreneurship, and its highly skilled and exceptionally talented professionals, the existing infrastructure, and the government incentives. Since $2012 \$ 140$ billion has been poured to venture capital investment in tech hubs and tech startups, and it endlessly innovates with its culture of constant reinvention and disruption. It has inspired the world in closing global skill gaps and solve the problem of wealth and income inequality, especially through tech hubs and startups. Therefore, similar replications are made in many parts of the world; for examples: Caohejing Hi-Tech Park in Shanghai, the Isar Valley in Munich, Silicon Plateau in Bangalore, The Toronto-Waterloo Corridor, and Surry Hills in Sydney.

\section{B. The Street as a Mirror of the Society}

CST is a task utilizing commercial signage found on highway roadsides as a source for a comparative learning experience; especially how commercial signs found in two different environments can reflect two different cultures, two different activities and production. In this activity students probe into and extract the hidden socio-cultural, psychological and historical information from commercial signage, which is taken for granted in everyday routines. The main reason is that the street can be a mirror of a culture.

Culture is defined from diverse perspectives, but all share the social character and social production of the people as basic elements, which include the intellectual and artistic aspects of a society [3]. In its broadest sense it is a set of qualitites which define the social and productive dimension of a society, such as the shared values, belief, habits and behaviour characterising the life of people [4]. Therefore, a society's activities and characteristics are reflected in what is visible on the streets. There is always a correlation between geographic space and society: what they do, how organized they are, their lifestyle, their environmental awareness, and their quality of life, to mention some. Public spaces are a mirror of a society, and it is also a medium that influences and completes the cultural profile of a society [5].

In short, signage including public signs and advertisements as visual materials found on the roadsides also reflect the social culture and cultural preferences that exist and diffuse into the everyday life of the society that they serve [6]. The content and the characteristics of those signs can starkly vary from one street environment to another, and from one street function to another.

\section{Commercial Signage: an Innovative Learning Resource}

The present task also utilizes commercial signage which is abundantly around us, although it has been criticised for influencing consumers' buying behaviour which may lead to materialism and even hyper-consumerism.

In fact, commercial signage is developed based on the principles of attention getting [9]. Therefore, it can also shape and reinforce the audience's impression not only on a product advertised, but also world views, attitudes towards themselves and the world around them--what is ideal and what is undesirable [10].

In contrast, this paper shows that commercial signs can be a good learning resource to raise students' awareness of digital disruption. In fact, commercial signage is also part of human communication [7] in reflecting culture and behavior in a certain situation [8]. Innovativeness and simplicity always exist in commercial signs, while the idea of helping students to understand the concept of disruptive innovation is helping students comprehend complex ideas using more effective, simpler, preferable, hands-on strategies that are interesting to students.

\section{Preparing the Students for the Age of Disruption: Learning from the Street}

Outdoor top down signs by public authorities and bottom up signs by private businesses in the form of billboards and banners on the roadsides of highways are always outstanding in size, with theme or product identification, simple message, and creative illustration to attract motorists in fast-moving cars, although they may never take them seriously, and quickly fade from their minds. In this task, however, students are supposed to engage themselves in the contents of those signs and seriously reflect the visible and invisible culture and behaviour of the society that produces them. They compare and interpret to make themselves aware of what is going on in the age of disruption, and how they should respond to it in the hyper-competitive world. In social studies students' observation behavior is part of their inquiry based learning.

Students' response is not only for preparing their own personal success but also for their country. They have to get ready to prepare themselves to represent their country as global leaders and as active accelerators in broader application of ICT and digital technologies.

\section{E. Points for Students to Know about Digital Disruption}

Almost all students have experienced themselves the benefit of the scientific and digital technological advancement, and all of them should always be aware how they depend on technology and how large technology may 
impact their daily life. New dramatic revolution in information and communication technologies enables boundless number of people to get connected, to create, access and share vast amount of data almost instantaneously. The speed of communication steadily accelerates, and the impact gives both advantages and disruption, that is the change of life order in society. When a society is not ready to adapt to the driving force of disruption, disruption becomes a threat instead of an opportunity. Although the term digital disruption holds a negative connotation, as it sounds loomingly intimidating. In reality it is unnecessarily as threatening as it sounds. It does not attack anyone's livelihood, as long as he does not ignore or stop it, but wisely utilises it, and uses it to his advantage. According to the McKinsey Global Institute's prediction in 2020 there will be digital new jobs that lack of 40 million high skilled workers and 45 medium-skilled workers globally.

\section{F. Points for Students to Know About Indonesia's Digital Readiness in the Age of Disruption}

Every country's readiness and competitiveness to protect itself from the threat of the age of disruptive era is determined by the country's readiness in adopting and developing digital technology. With the present condition students should be aware that in general Indonesia is not fully ready for the age of disruption. This unreadiness will widen economic inequality between Indonesia and countries with digital advancement, and, internally in Indonesia, between those who are ready and those who are not. Students must also be aware that they have to get ready with new jobs that will appear during the disruption.

For the last 30 years, every year Institute of Management Development (IMD) presents the digital competitiveness ranking to assess the extent how 63 countries with high or middle levels of income per capita adopts and explores digital technologies leading to transformation in government practices, business models, and society in general. Three factors were evaluated: knowledge, technology and future readiness for the overall rankings. Knowledge is defined as know-how necessary to discover, understand and build new technologies; technology is the overall context that enables the development of digital technologies, and future readiness is the level of country preparedness to exploit digital transformation. Knowledge comprises three sets of factors: talent, training and education, and scientific concentration. Technology covers regulatory framework, capital, and technological framework. Future readiness consists of adaptive attitudes, business agility and IT integration.

When 29 countries with populations greater than 20 million were ranked, it was discovered that Indonesia ranked the 28th for the World Digital Competitiveness Rankings-only one rank higher than the lowest in the list. Compared to other ASEAN countries, Indonesia is below Malaysia that ranks the 10th, Thailand the 14th and the Philippines the 23rd. Concerning knowledge or the know-how to discover, understand, and build new technologies, among 63 countries, Indonesia ranked the 61st. Compared to other ASEAN countries evaluated, Singapore is at the top of the ranking list, Malaysia the 17th, Thailand the 44th, and Philippines the 50th. Concerning future readiness, Singapore ranks the 15th, Malaysia the 29th, Thailand the 49th and the Philippines is the 52th.

\section{G. Innovation and Awareness Raising}

Innovation should be contrived to help students understand disruption in a more concrete way using empirical evidence. Concrete understanding helps students get ready to enter the age of disruption. The first reason is that the concept of disruption can be too abstract for students to understand. It can even be more abstract when students have to understand the macro-level of global competition among nations [11]. To make students understand and aware of the immediacy of the importance of the concept, teachers need to innovatively demystify it into a very alive and real context that students can comprehend, develop their curiosity and their passion-driven learning, and sensitiveness to social problems.

Another reason is that teachers today are supposed not to be fearful to experiment and to innovate although the output might not fit the existing standard requirements; that is the uniformed, comparable and regulated measurement [12]. In the test-driven world of education today, teachers have been much motivated to focus on raising students' standardized test scores, while untested meaningful learning experience have been much ignored [13].

\section{AN EXAMPLE OF CARRYING OUT THE TASK: COMPARING MALANG-SURABAYA AND SAN FRANCISCO-SAN JOSE}

\section{A. The Old Highway Connecting Malang to Surabaya}

To provide an example of the task proposed, the commercial signs on the highway that connects Greater Malang to Surabaya is compared to the expressway that links San Fransisco and Silicon Valley. The $80 \mathrm{~km}$-freeway to link Malang and Surabaya was still newly inaugurated two months earlier, and no billboards are found along the roadsides of the expressway. Therefore, the old highway which was always in heavy traffic between Malang and Surabaya was explored; it passes the districts of Singosari, Purwodadi, Gempol, and Porong. More than 20 thousand cars each day pass the highway.

The Greater Malang or Metropolitan Malang consists of Malang City, Batu City and the Regency of Malang, which totally cover an area of $3000 \mathrm{~km} 2$. About 3 million people living in Greater Malang. Malang City Proper is the second largest city in the province, and the 10th largest in Indonesia, situated in an area as large as $145,28 \mathrm{~km}^{2}$. The population of 
the city is growing rapidly to about 1.2 million. Surabaya is the second largest city in Indonesia and is the capitol of the Province of East Java; the economic growth of Surabaya always exceeds the national economic growth, and one of the highest in Indonesia. In 2014, for example, it was $6.73 \%$ exceeding the national economic growth of $5.02 \%$.

\section{B. Silicon Valley: San Fransisco-San Jose}

The highway that connects San Fransisco to San Jose is a portion of Route 101--a coaster north-south route-stretching from Los Angeles California to Tumwater, and known as Bayshore Freeway, Santa Ana Throughway, and James Lick Freeway. It passes Santa Clara, Redwood City and Sunnyvale. San Jose is the capitol and the third largest city in the Valley, one of the most affluent counties in the USA, and the tenth largest in the country with the third highest GDP per capita in the world.

Silicon Valley covers a region with about 50 cities in the southern part of the San Fransisco Bay Area, and is the home base of the global computer technology including silicon chip technology, computer design, apps, smart phones, social medias, etc. It is also home to Google and Facebook, and one of the centers of innovation, scientific research and development, high tech industry, and social media in the world. It houses high tech corporations and thousands of startup companies. Almost everyone works in information technology.

As students may obviously have financial and time restrictions to visit Silicon Valley, Google Maps, which has excellent mapping coverage, is practical to utilize. Today with the emerging geo-referenced big data from the Internet, geospatial research is very easy. Students just need to be familiar with how to use new technology for their learning, including how to optimize the use of Google Maps for their learning $[14,15,16]$.

\section{Methodology in Counting the Number of Signs, Types of Outdoor Signs Investigated, and Areas of Investigation}

A sign produced by one company or institution to advertise one product can appear more than one time. A company can also produce different kinds of signs for one product. Then, those signs are only counted as one sign. However, if one company produces different brands of products, and advertised them separately, they are counted accordingly.

The signs investigated consisted of permanent billboards, wall signs, and large size vertical and horizontal banners along the Surabaya-Malang highways or Jalan Raya MalangSurabaya that made up the portions of Singosari, Lawang, Purwosari, Purwodadi, Pandaan, Gempol, Porong.

\section{Classifying Signs into Business Sectors According NAICS Code}

Using the classification system of NAICS codes (North American Industry Classification System, USA 2017), the signs found are grouped as shown by Table I and Table II. The production-oriented classification system is used in USA, Canada and Mexico based on 2017-2022 three economic activities: new and emerging industries, service industries in general, and industries engaged in the production of advanced technologies. The classification is used for its up-to-dateness and to make students aware of the business areas they can enter and to prepare themselves for their future success.

In the classification system, the manufacturing sector, for example, consists of subsectors. One important subsector is Computer and Electronic Product Manufacturing, which brings together industries producing electronic products and their components. The manufacturers of computers, communications equipment, and semiconductors, are grouped into the same subsector because of the inherent technological similarities of their production processes, and the likelihood that the forementioned technologies will continue to converge in the future. NAICS acknowledges the importance of electronic industries, with their rapid growth over the past several decades and the likelihood that the industries will, in the future, become even more important in the economies of the three North American countries.

\section{E. The signs Found on Malang-Surabaya Highway}

Eighty-three signs were collected. They were all (100\%) related to basic needs, even thirty-six signs (43.37\%) were for immediate basic needs, like food, clothes, and shelter. It is interesting that the most dominant classification found was public administration (11\%), followed by education (10\%) and tobacco products (10\%). It was discovered that the government made a relatively high number of regulation, reminder, and suggestion signs. They all belong to the public administration sector ( 9 signs). Signs from manufacturing companies were dominant on the highway, amounting to thirty-one signs $(37.34 \%)$. But all those signs were all related to traditional manufacturing industries: tobacco products (8), beverages (6), food (4), apparel (3), soap and toiletries (2), paint and coating (3), bakery (1), and plastic factory (2). Services are also related to both immediate and modern basic needs: food services (6), accommodation (3), education (8), real estate and rental service (6), healthcare services (5), religious alms-giving services (3), and internet service (2). Other signs were for amusement parks (3), and retail trade: non-store (2), home center (2) and tire shops (1). There were neither advanced technology-based manufacturing, nor professional, scientific and highly technical services found in the signage. 
TABLE I. THE SIGNS FOUND ON THE OLD HIGHWAY TO CONNECT MALANG TO SURABAYA

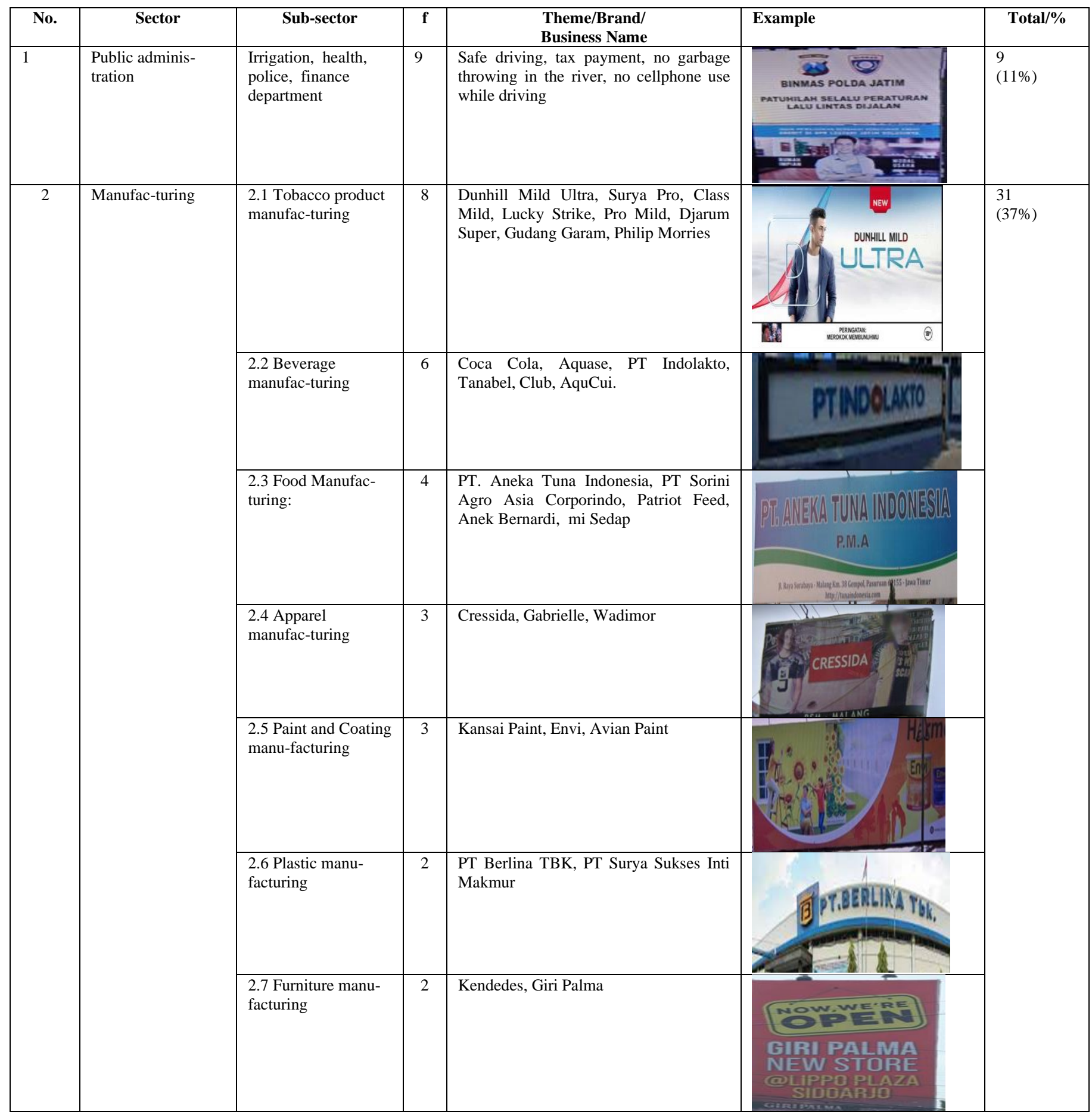




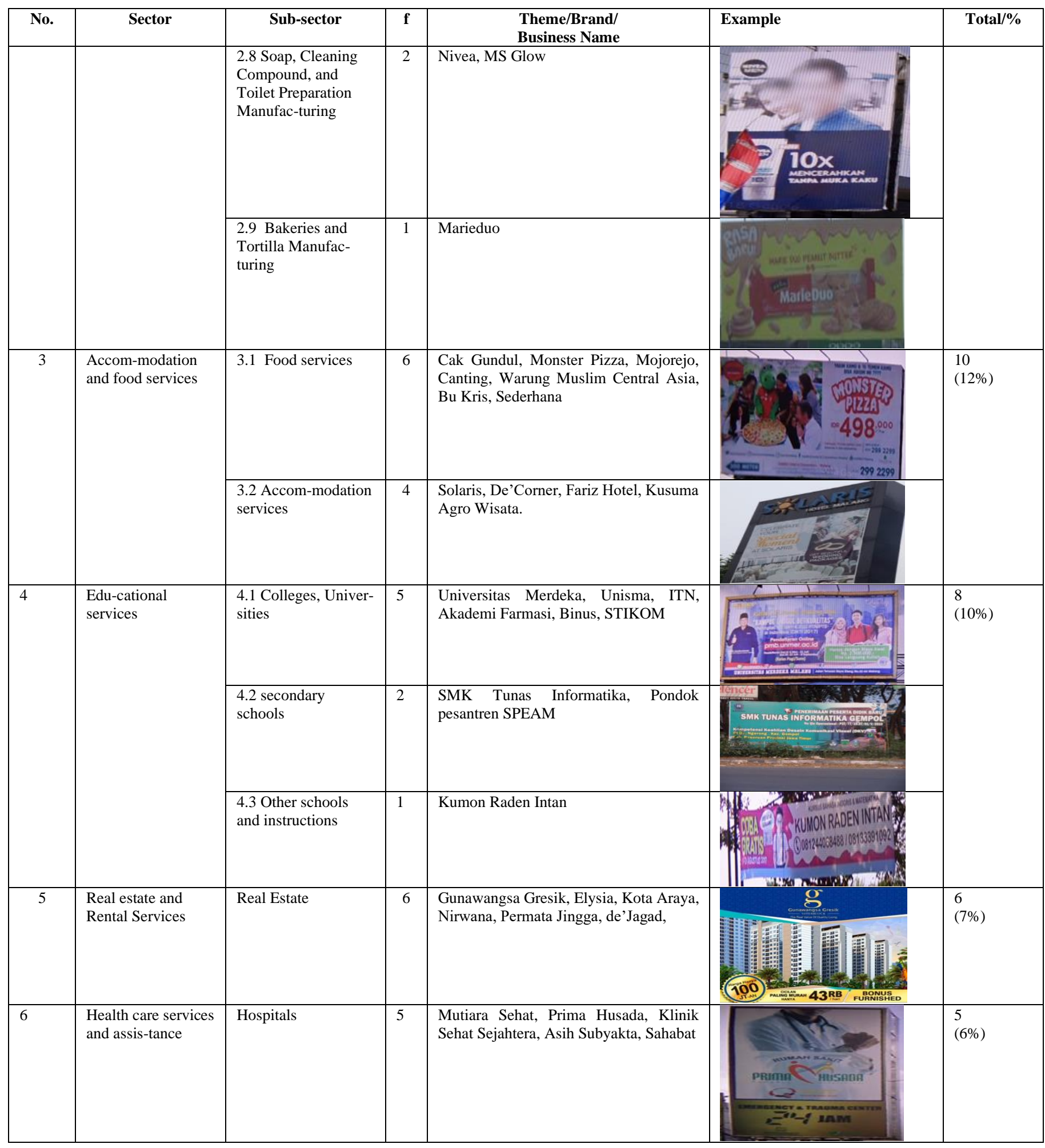




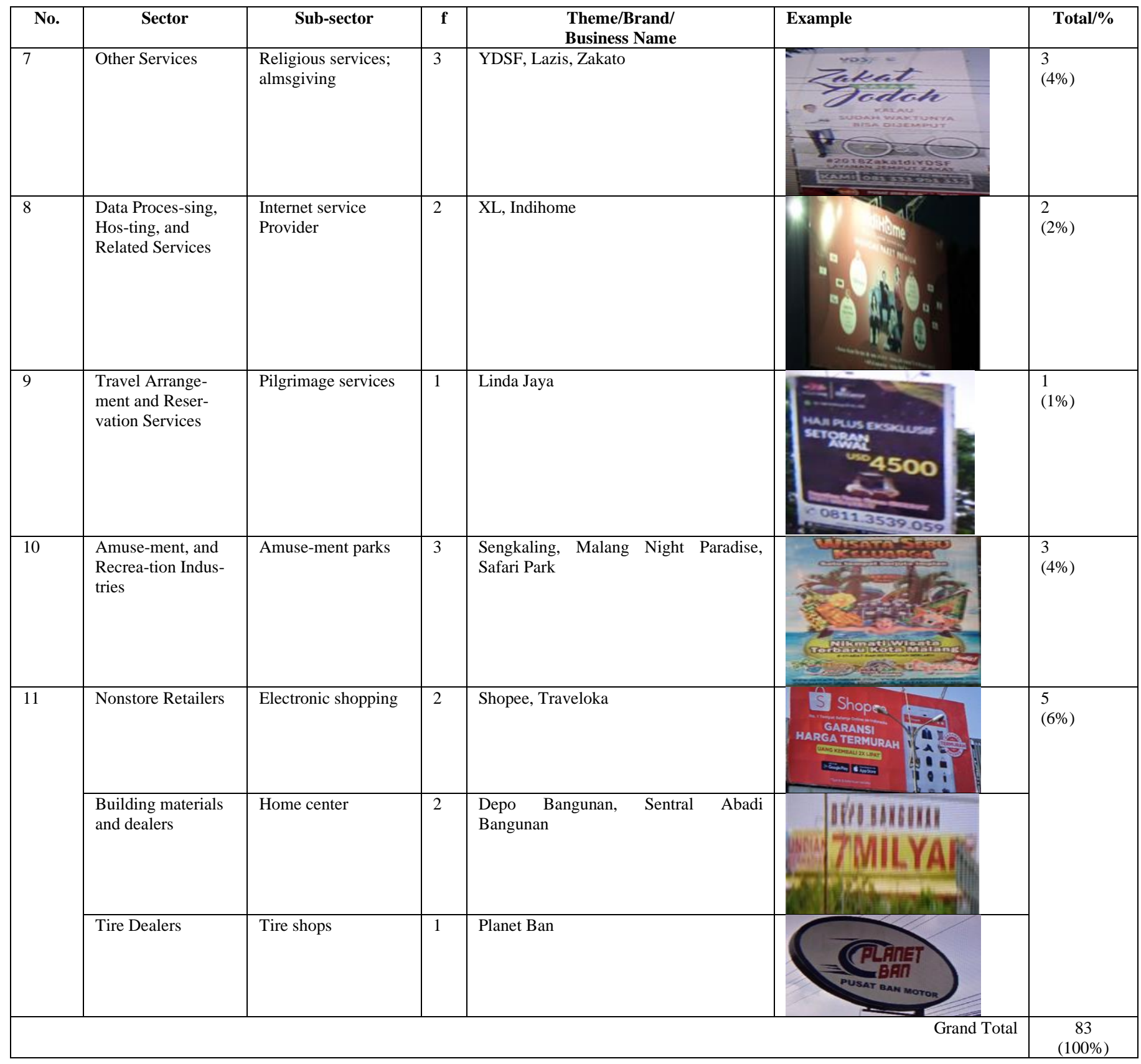

\section{F. The Signs Found on Silicon Valley}

There were 45 signs found on the expressway. Computing science and technology was very dominant in the content of the signs. Forty percent of the signs were installed by the service and manufacturing companies in the field of computing technology: custom computer programming (6), computer system design (3), management software (1), software publisher (1), computer graphic design (1), data management (1), semiconductor technology (2) and digital signal processing (1). Only four signs (9\%) were for traditional services related to immediate basic needs of food and drink: brewery (1), food and drinking places (3).

Sixteen signs $(36 \%)$ were for service industries that require professional, scientific, and technical services: custom 
aumobile industry, producing electric and semi-self-autodriving cars, known for its sustainable energy. The rest one sign was for brewery.

The rest fourteen signs (31\%) were for advertising amusement and recreational industry: theme park (2) and casino (1); healthycare services: dental clinic (1), diagnostic imaging center (1), medical laboratory (1); retailing: truck dealer (1), electronics and appliance store (1); commercial bank (1); facilities support service (1); employment service (1); mobile money service (1) and performing arts (1), as shown in Table 2.

TABLE 1.

SIGNS FOUND ON A PORTION OF ROUTE 101 TO CONNECT SAN FRANSISCO TO SAN JOSE IN SILICON VALLEY

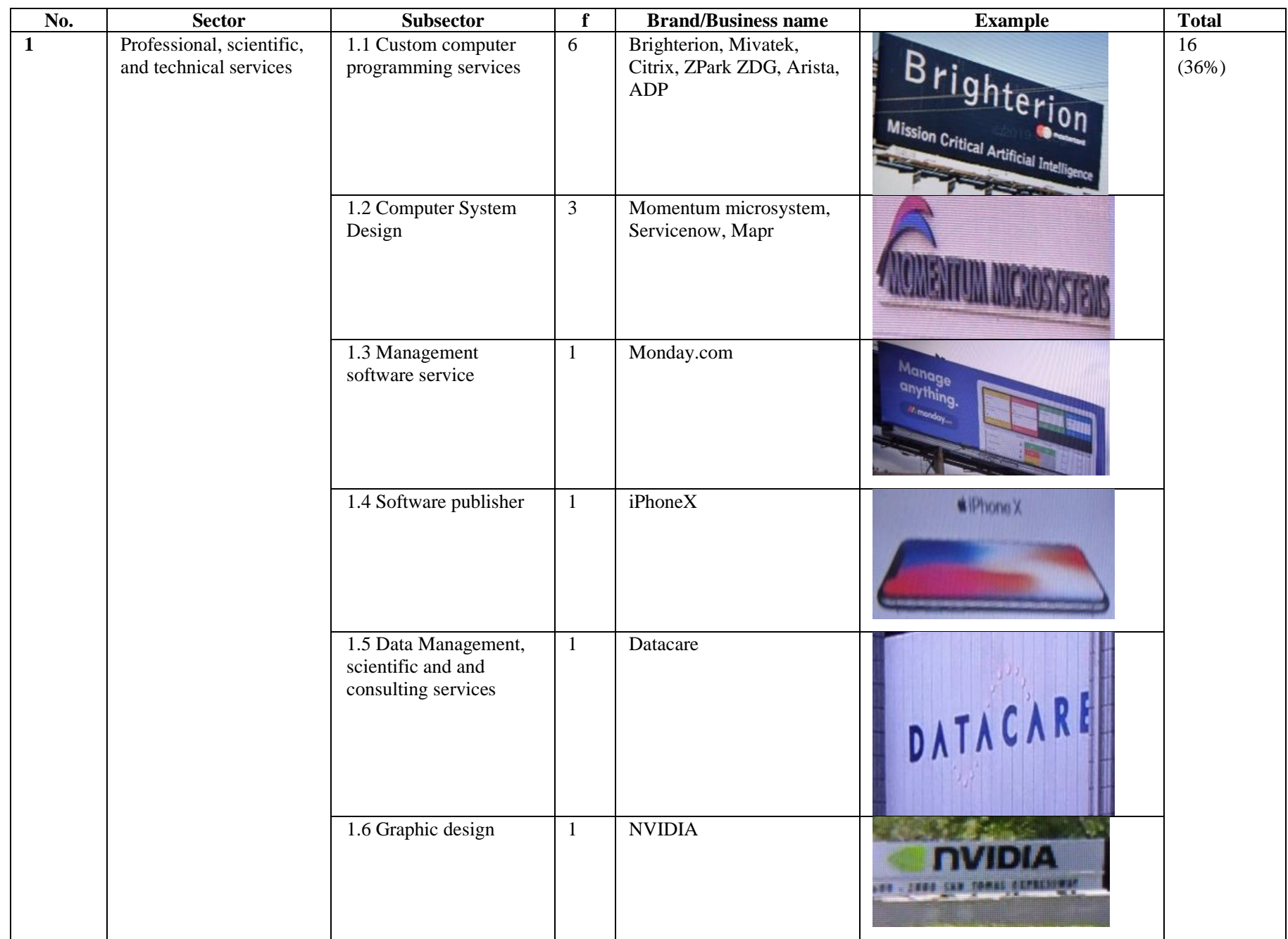




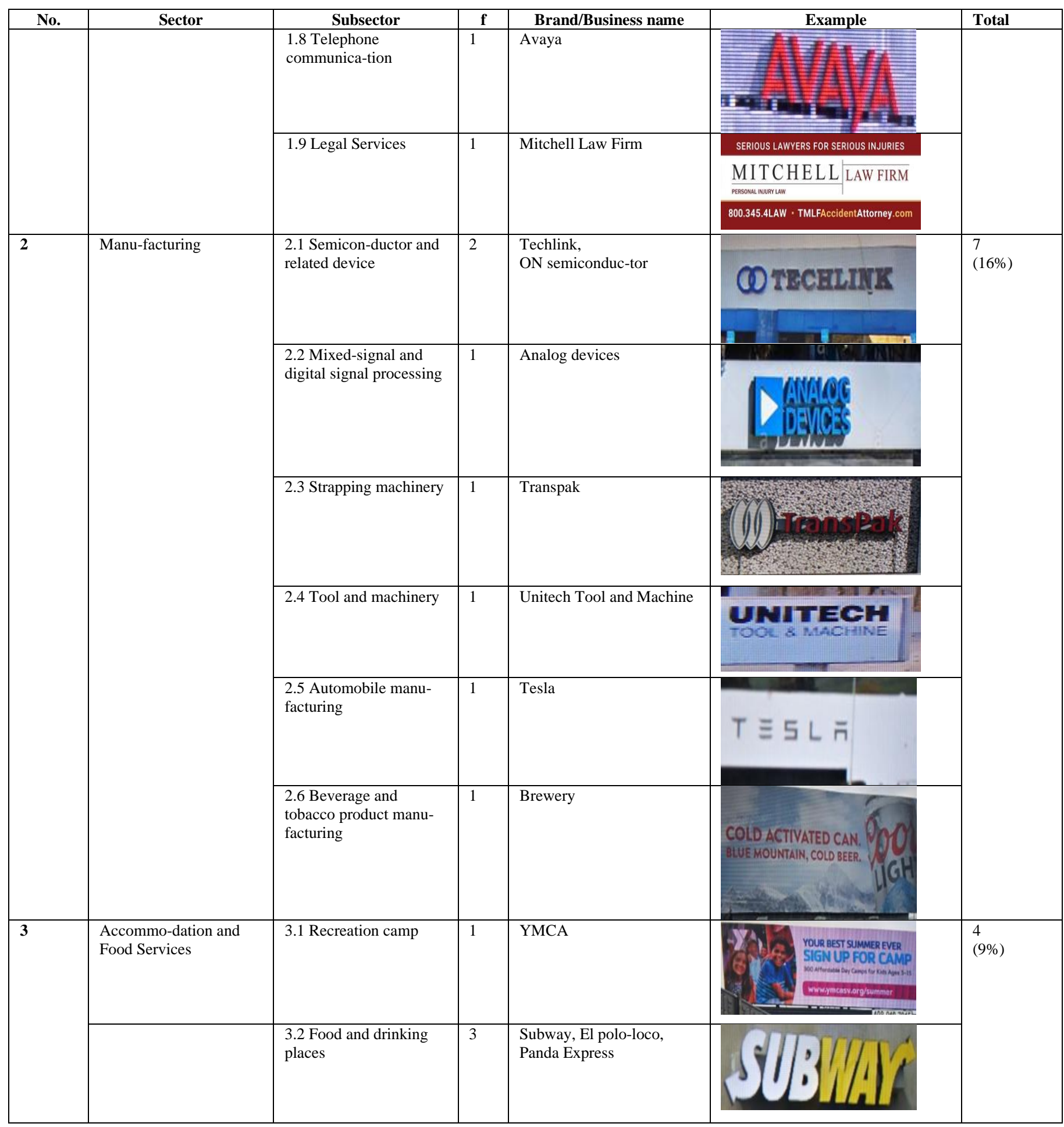




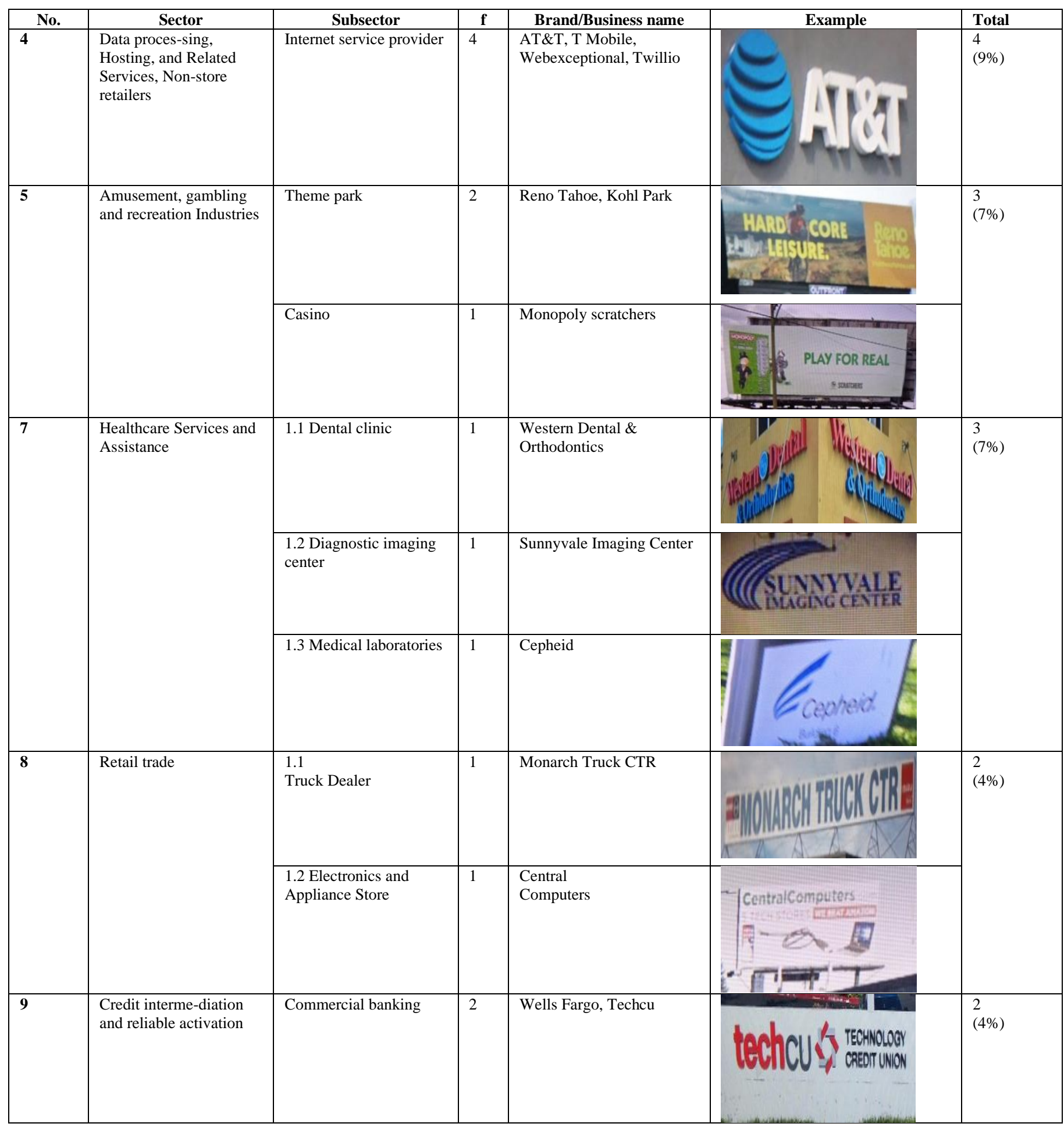




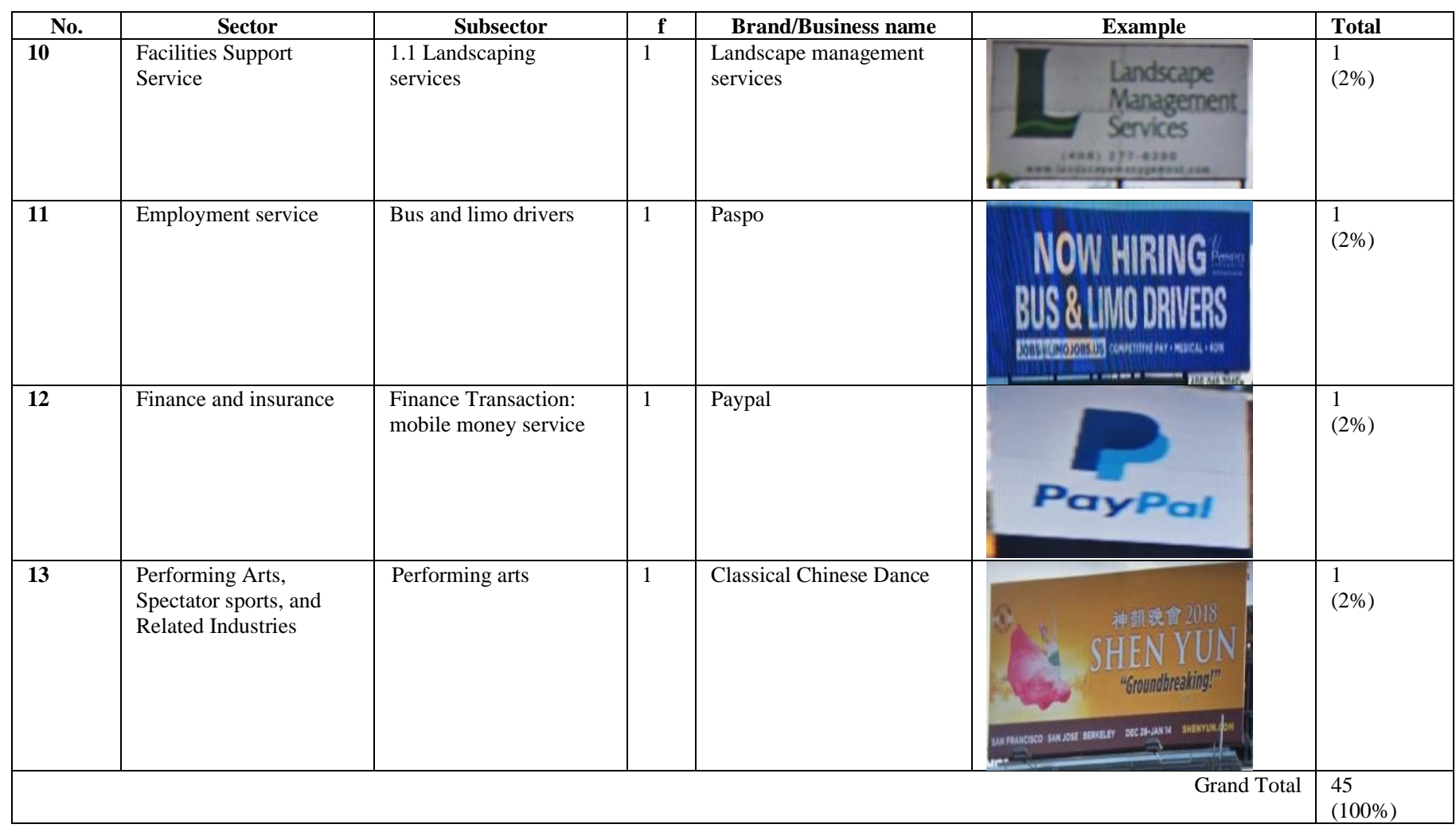

\section{ANALYZING, EVALUATING AND}

\section{EXPLAINING THE FINDINGS: MALANG-SURABAYA AND}

\section{SILICON VALLEY}

It is obvious that the signage of Malang and Surabaya reflects traditional manufacturing activities, while the signage in Silicon Valley reflects the advanced manufacturing activities. There is a contrast between traditional and advance manufacturing. Traditional menufacturing includes chemicals, machinery, electrical equipment, plastics and rubber, and fabricated metals, while advanced manufacturing industries are development-intensive, such as semiconductors, communications equipment, computers, pharmaceuticals, and medical devices [17].

\section{A. Tobacco Product, Brewery and Casino Signs}

Malang was dominated by the signs of tobacco products which was absent in Silicon Valley. In constrast, Silicon Valley had a brewery sign and a casino sign which were absent in Malang. This is to indicate that cigarette industry was important in Malang-Surabaya area and extensive advertising of tobacco was not prohibited although zone restrictions were already issued.

Discussing about what is reflected from the tobacco signs in Malang-Surabaya and Silicon Valley, it seems that the number of smokers in Indonesia is on the rise, and they become the marketing targets of cigarette factories. The industry also plays an important role for the economy of Malang-Surabaya region. In contrast, Silicon Valley is the center of innovative industries, and tobacco is not in their interest, and there is also an anti-smoking culture in Silicon Valley, although the Silicon Valley $e$-cigarette startup Juul is surging in popularity through social media.

According to the Financial Times, April 2019, among the top 10 countries where tobacco smoking is prevalent for people as young as 15 years and older, Indonesia ranks the second and USA ranks the ninth. According to the Indonesian Ministry of Industry tobacco is still one of the largest sources of revenue for the country, and plays a major role for labourintensive opportunity, and for tobacco and clove farming. So far tobacco industry in Indonesia is still one of the largest spender for outdoor advertising. Therefore, it is not surprising if the WHO in 2017 ranked Indonesia the third in the world for total number of smokers. A staggering 67.4 of male adults, and 41 percent of children between 13 and 15 were smokers.

In Silicon Valley, however, as part of USA, the absence of tobacco product advertisement is mostly because of the Family Smoking Prevention and Tobacco Control Act, signed 
ICT-based road traffic monitoring devices needs high-cost by President Barack Obama in 2009, regulating the manufacturing, marketing, and sale of tobacco products. Also, Silicon Valley is the global center of high technology industry and innovation, where they were not interested in tobacco product industry, which has also received pressures from the anti-smoking efforts by the federal government.

Because of religious reason, beer sales are restricted in Indonesia, including in Malang. It is not available in shops and convenient stores. In contrast, beer is a popular drink in USA and widely advertised, including in Silicon Valley. With the same reason, gambling is illegal in Indonesia, no sign is found for gambling. On the contrary, although gambling can be harmful, gambling is an entertainment activity in USA, and is quite commonplace.

\section{B. Law Abidance: in Malang-Surabaya vs Silicon Valley}

It is interesting that top-down signage like regulatory and warning signs for traffic, public safety and garbage disposal were not found in Silicon Valley, but they made up a high proportion in Malang-Surabaya.

The USA has robust laws regulating littering and garbage disposal, law is strictly enforced, as President Abraham Lincoln said, "Laws without enforcement are just good ideas." Besides law enforcement, education and serious cleaning up are equally vital. There is a saying in English that children in English -speaking countries learn in school: "litter begets litter." Plastic dumping anywhere, for example, is illegal in USA, and violators are liable for a stiff civil penalty and even imprisonment. In some places they are also charged with social sanctions, such as collecting garbage. Fines start at $\$ 50$ for minor offenses and can reach up to thousands of dollars. Law enforcement are continuously stepped up, and hidden cameras are strategically positioned at some places.

In general American culture is known to be more ecofocused than Indonesian culture; American people have higher environmental awareness, and they have learned more about how to obey the law. In Indonesia we can easily see piles of garbage on the ground and in river streams. This tendency depends much on the people's educational level and sociocultural background. For example, the socio-demographic characteristics of the urban poor have been associated with the tendency of littering behavior [18].

Next to garbage disposal warning signs, for reducing societal losses from vehicle crashes, driver warnings using billboards and banners are more needed in Indonesia than the USA, because in USA traffic is remotely controlled using ICT-based road transportation safety systems [19]. The penalty structure for breach of traffic rules, stiff traffic fines, and license suspensions in the USA have been successful to decrease traffic rule violations and increased revenue collection. A routine ticket for speeding or failure to stop at a stop sign will cost up to USD400. infrastructure investment. This is the main reason that it has not been utilized in Indonesia, except in some smart cities, like Jakarta, Bandung and Surabaya, which have installed traffic cameras to record violations. No cameras are found in Malang-Surabaya old highway.

\section{Focus of Manufacturing in Malang-Surabaya vs in Silicon Valley}

Signs from manufacturing companies on MalangSurabaya highway were dominant in number $(37 \%)$, but all those signs belonged to traditional manufacturing industries, especially food, beverages and apparel. This is quite in line with the national fact. One of the six main manufacturing output in Indonesia is food and beverages, that makes the largest industry in Indonesia and accounted to almost thirty percent of the country's manufacturing output [20].

Indonesian manufacturing output was in contrast with Silicon Valley's; half of the signs in Silicon Valley were installed by the service and manufacturing companies in the field of computing technology, and heavy industry, including the futuristic automobile manufacturer TESLA, which for its leading semi-autonomous technology produces different cars in terms of safety, design, and vehicle emissions. There were one internet provider sign and one online shop sign on Malang-Surabaya highway; this is to reflect that the people already adopted internet technology. However, an internet provider is a data processing service and an online shop is a retail electronic commerce; both utilize advanced technology, but they are not an industry that manufactures hightech devices.

That Malang-Surabaya signage showed that the manufacturing companies were generally still categorised as traditional manufacturing industries related to immediate basic needs and modern basic needs, they were actually in line with the Roadmap "Making Indonesia 4.0" launched in April 2018 by President Joko Widodo. The five priority industries in the Roadmap are food and beverage industry, textile and apparel industry, automotive industry, electronics industry and chemical industry. The focused technologies to boost and to adopt in the roadmap to get ready for Industry 4.0 are internet of things, robotics and automotion, big data and cloud computing, human machine interface, advanced production methods. Infrastrucutre and technology are crucial to boost, especially for building advanced automotive, electronics and aerospace industry. They need to transform their operations from low-tech assembly to high-tech, high-value component manufacturing. The 3rd industrial revolution already utilizes electronics and IT but the 4th industrial revolution has gone into merging real and virtual worlds.

The five priority industries are not Industry 4.0 proper, and is insufficient for the challenge of the potential disruption. However, they are important manufacturing industries to 
adopt in the roadmap, as a bridge to speed up the implementation of Industry 4.0 and make Indonesia one of the world's 10 biggest economy by 2030. The roadmap is realistic, export oriented, and strategic according to the present readiness level of new types of IT infrastructure, the shortage of new talent requirements for technical specialists, limited funding to invest on new technology and infrastructure, to mention some. They are the bridge to keep abreast with other Smart Nations for the modern emerging Industry 4.0 which should be successful to reduce the cost of production through the utilization of advanced internet technology, artificial intelligence, advanced robotics, wearable technologies, sensor technology, drones, nanotechnology, and 3D printing.

Areas like Silicon Valley with its outstanding signage on advanced computing technology is going to reap significant economic benefits in the long run. However, nations that are slow to embrace digital technology run the risk of falling further behind in short order. Indonesia is still at its nascent stage of digitization; and the paradox is that the digital denizens are one of the most active in the start-up ecosystem, but the rest lags in utilizing modern technology. ICT infrastructure is still limited; internet penetration is still low; Indonesia is still short of skilled tech talents [21].

\section{Human Resources Readiness}

Some traditional jobs are destroyed while new jobs and economic activities are generated in Industry 4.0. such as mobile, cloud computing, analytics, intelligent automation, artificial intelligence (AI), the Internet of Things (IoT), 3D printing, autonomous robotization, and augmented- and virtual reality (AR/VR). The signage found in MalangSurabaya did not reflect that modern economic activities have strongly entered Malang-Surabaya region. Most of the economic activities shown on the signs were those called by McKinsey as the most vulnerable during the shift to Industry 4.0, such as physical labour, retail, accommodation and food services. The signs in Silicon Valley, in contrast, indicated how the people have harnessed the potential of Industry 4.0 into a wide range of jobs, skills, tasks, occupations, and employment in highly professional, scientific, and technical services shown in Table II. This indicates that the manufacturing environment in Malang-Surabaya regions is still not fully ready for the future of production, to bring Indonesia to be one of the global leading economies.

\section{CONCLUSION}

To withstand our high school and university graduates to digital disruption, students need awareness raising activities which energize and prepare themselves for the digital disruption in Industry 4.0. This paper proposes an innovative instructional strategy on social studies, called "A Comparative Signage Task in Geographic Space" for cultivating students' awareness and sensitiveness to social phenomena and social problems, and make themselves part of the solution by raising their own standards and achievement for their future innovation.

In the task, students compare the linguistic landscape signage on an Indonesian highway, like Malang-Surabaya old highway, with a portion of US Route 101, in Silicon Valley. The Expressway in Silicon Valley is used as the benchmark for the area's leadership on high technology, tech talents, and leading potential to survive in the digital age. Students use Google Maps to explore the Silicon Valley Expressway. The task is developed to connect students' classroom learning with the real world. Besides raising students' awareness and readiness, the task also promotes students' higher order thinking skills, such as creating, evaluating and analysing to survive in the age of disruption. Using the integrative approach students have the experience of observing, interpreting and explaining social phenomena from different relevant aspects, such as education, economy, culture, finance, health, and state policy. Strong reading and study skills are crucial for interpretation and explanation. This practice is also important to prepare students to be life-long learners in the age of disruption.

To exemplify how the strategy works, this paper compared Malang-Surabaya old highway with Route 101 of Silicon Valley; 83 signs were collcted from Malang-Surabaya Old Highway, and 45 signs were collected from Silicon Valley. The signs collected were classified based on the NAICS Code System-- Standard Industrial Classification. It was discovered that the signage found in Malang-Surabaya and the one found in Silicon Valley could really represent the economic activities and the sociocultural situations in the two contrasted regions. A rigorous literature review from different perspectives was conducted to analyze, evaluate and to explain the comparative findings from various relevant perspectives, such as economics, law, business, health and safety, cultural psychology, sociology, traffic control system, computer science and technology, machine tools and manufacturing, etc.

It is concluded that the proposed "A Comparative Signage Task in Geographic Space" is an effective instructional strategy for raising students' awareness, developing students' high order thinking skills, and study skills, to prepare themselves to withstand, deal and manage the age of disruption.

\section{REFERENCES}

[1] C.M.Christensen, S.Aaron, W. Clark. "Disruption in Education," 2001. Available from: https://er.educause.edu/-media/files/ articles/2007/1/erm0313.pdf?la=en\&hash=F36B08C108E63EE7321F FA4DA64E8E53471B9EAD

[2] S.N. Ikwumelu, O.A. Oyibe, E.C. Oketa, E. C. "Adaptive Teaching: An Invaluable Pedagogic Practice in Social Studies Education," Journal of Education and Practice. vol.6, no.33, pp.140-144, 2015. 
[14] S. Kweldju. Using Googlemaps for Linguistic Landscape Activities in Self-Access Center: Improving English Department Students' Competencies. Proceedings of the 4th International Conference on Human-Computer Interaction and User Experience in Indonesia, CHIuXiD'18, pp. 89-92, 2018.

[15] S. Kweldju. Autonomously Riding Google Maps to Travel to English Speaking Countries: Linguistic Landscape. Journal of English Language, Literature and Teaching, vol.2, no.1, pp.5-13, 2018b.

[16] S. Kweldju, "Using Geosemiotic Approach, Learners Create Their Own Linguistic Landscape for Developing Multimodal Competencies: Task-Based," Journal of English Language, Literature and Teaching, in print.

[17] G. Tassey, "Competing in Advanced Manufacturing: The Need for Improved Growth Models and Policies," The Journal of Economic Perspectives, vol. 28, no.1, pp. 27-48, 2014.

[18] H.Arafat, I.A. Al-Khatib, R.Daoud, and H. Shwahneh, H., "Influence of socio-economic factors on street litter generation in the Middle East: effects of education level, age, and type of residence," Waste Management and Research, vol.25, no.4, pp. 363-70, 2007.

[19] J.L.Gifford, "ICT and road transportation safety in the United States: a case of American exceptionalism," IATSS Research,vol.34, no.1, pp. 1-8, 2010.

[20] Business Sweden. "Industry 4.0 in Indonesia: Market Opportunities, Future Trends and Challenges," The Swedish Trade and Invest Council. 2017. Available from: https://www.businesssweden.se/globalassets/indonesia-industry-4.0.pdf.

[21] K.Das, M.Gryseals, P.Sudhir, and K.T. Tan, KT, 2016. Unlocking Indonesia, Digital Opportunity, “ Jakarta: McKinsey Indonesia Office. 2016. Available from: https://www.mckinsey.com/ /media/McKinsey/Locations/Asia/Indon esia/Our\%20Insights/Unlocking\%20Indonesias\%20digital\%20opport unity/Unlocking_Indonesias_digital_opportunity.ashx 